\title{
Considering Square Difference Labelling for Validating Theta Graphs of Dynamic Machinaries
}

\section{P. Jagadeeswari}

Abstract: In this work, we prove that the graphs $Z-P_{n}$, braid graph, switching of an apex vertex of $\mathrm{CH}_{n}, T_{i=} \odot K_{2}$, bull graph $\left(C_{n}\right)$, truncated tetrahedron, frutcht graph are Square difference graph (SDG).

Keywords: Square Difference, braid graph, truncated tetrahedron, frutcht graph, Bull Graph, AMS classification: $05 C 78$

\section{INTRODUCTION}

Throughout this paper, we utilize simple, undirected and finite graph. In this paper and we follow [2,3,8]. Square difference labeling are studied in [9, 10]. N. B. Rathod proved $\mathrm{Z}-\mathrm{P}_{\mathrm{n}}$, braid graph, triangular ladder are 4- cordial [7]. Bull graph, shell graph flag graph for L cordial were proved in [6]. Jagadeeswari et. al. proved square difference labeling for pyramid and $\mathrm{H}$ graph [4,5]. Subashini proved theta graph admits square difference labeling [11]. In this work, we prove some various graphs for Square Difference Labeling.

We present some definitions, which are helpful for our work.

\section{Definition 1.1.}

A function of a graph $\mathrm{G}=(\mathrm{p}, \mathrm{q})$ is said to be a Square difference graph (SDG), if it admits a bijective function $f$ : $\mathrm{V}(\mathrm{G}) \rightarrow\{0,1,2---p-1\}$ such that the induced function $f^{*}:$ $\mathrm{E}(\mathrm{G}) \rightarrow \mathrm{N}$ given by $f^{*}(u v)=\left|[f(u)]^{2}-[f(v)]^{2}\right|$, $\forall u v \in E(G)$ and the edge labels are distinct.

\section{Defintion 1.2.[1]}

The graph $\mathrm{Z}-\mathrm{P}_{\mathrm{n}}$ is obtained from the pair of paths $P_{\mathrm{n}}^{\prime}$ and $P_{\mathrm{n}}$. Let $\mathrm{v}_{\mathrm{i}}$ and $\mathrm{u}_{\mathrm{i}}, i=1,2, \ldots \mathrm{n}-1$, are the vertices of path $P_{\mathrm{n}}^{\prime}$ and $P_{\mathrm{n}}^{\mathrm{p}}$ respectively. To find $\mathrm{Z}-\mathrm{P}_{\mathrm{n}}$ join $\mathrm{i}^{\text {th }}$ vertex of path $P_{\mathrm{n}}^{\prime}$ with $(\mathrm{i}+1)^{\text {th }}$ vertex of path $P_{n}$ for all $i=1,2, \ldots \mathrm{n}-1$.

\section{Definition 1.3.[1]}

The braid graph $\mathrm{B}(\mathrm{n}),(\mathrm{n} \geq 3)$, is obtained by joining $i^{\text {th }}$ vertex of $P_{\mathrm{n}}^{\prime}$ with $(\mathrm{i}+1){ }^{\text {th }}$ vertex of $P_{\mathrm{n}}^{w}$ and $i^{\text {th }}$ vertex of $P_{\mathrm{n}}$ with $(i+2){ }^{\text {th }}$ vertex of $P_{\mathrm{n}}^{\prime}$ with the new edges for all $1 \leq i \leq n-2$.

\section{Definition 1.4.}

A closed helm $\mathrm{CH}_{\mathrm{n}}(\mathrm{n} \geq 3)$, is the graph obtained from the helm $\mathrm{H}_{\mathrm{n}}$ and adding a edges between the pendant vertices.

\section{Defintion 1.1.5.}

The truncated tetrahedron graph is formed with 12 vertices and 18 edges. It is connected cubic transitive graph.

\section{Definition 1.1.6.}

The Frutcht graph is formed with 12 vertices and 18 edges. It is a 3 regular graph and it has no non- trivial symmetries.

\section{MAIN RESULTS}

Theorem 2.1.

The graph $\mathrm{Z}-\mathrm{P}_{\mathrm{n}}$ is Square difference graph.

Proof:

Let the graph $Z-P_{n}$ has $2 n$ vertices and $3 n-3$ edges. Consider, $\mathrm{V}\left(\mathrm{Z}-\mathrm{P}_{\mathrm{n}}\right)=\left\{\mathrm{u}_{\mathrm{i}}, \mathrm{v}_{\mathrm{i}} / 1 \leq i \leq n\right\}$ and $\mathrm{E}\left(\mathrm{Z}-\mathrm{P}_{\mathrm{n}}\right)=$ $\left\{u_{i} u_{i+1}, v_{i} v_{i+1}, v_{i} u_{i+1} / 1 \leq i \leq n-1\right\}$

Define the mapping $f: \mathrm{V} \rightarrow\{0,1,2 \ldots . . n\}$ as follows:

$$
\begin{aligned}
& f\left(u_{i}\right)=2 i-1 \\
& f\left(v_{i}\right)=2(i-1)
\end{aligned}
$$

and $f^{*}$ for the above labeling is mentioned as:

$$
\begin{aligned}
& f^{*}\left(u_{i} u_{i+1}\right)=8 i \equiv 0(\bmod 8) \\
& f^{*}\left(v_{i} v_{i+1}\right)=8 i-4 \equiv 0(\bmod ) \\
& f^{*}\left(v_{i} u_{i+1}\right)=12 i-3
\end{aligned}
$$

Thus, all the edge labeling are distinct. Hence the theorem. For instance, the example mentioned below.

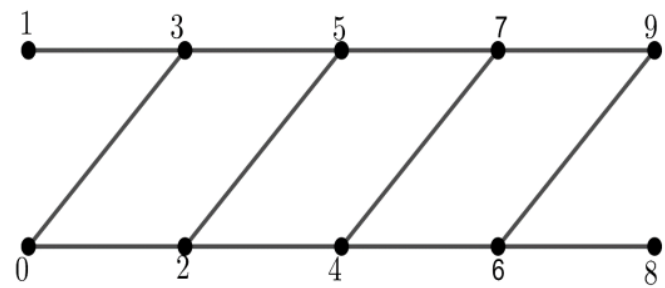

Fig. 1. SDL for $\mathrm{Z}_{\mathbf{5}}$ 


\section{Considering Square Difference Labelling for Validating Theta Graphs of Dynamic Machinaries}

\section{Theorem 2.2.}

\section{Proof:}

The Braid graph admits SDL.

Let $u_{1}, u_{2}, \ldots, u_{n}$ be the vertices of path $P_{n}^{\prime}$ and $v_{l}, v_{2}, \ldots, v_{n}$ be the vertices of path $P_{n}^{n s}$. Similarly, the edges of path be $u_{j} u_{j+1}$, $v_{j} v_{j+1}, v_{j} u_{j+l}$ and $u_{j} \mathrm{v}_{j+1}$. The bijective function of braid graph $f$ is given as:

$$
\begin{aligned}
& f\left(u_{j}\right)=2 j-1 \\
& f\left(v_{j}\right)=2(j-1) \text { for } 1 \leq j \leq n
\end{aligned}
$$

and the injective function $f^{*}$ is given below:

$$
\begin{aligned}
\text { for } 1 \leq j \leq n-1 \\
f^{*}\left(u_{j} u_{j+1}\right)=8 j \\
f^{*}\left(v_{j} v_{j+1}\right)=8 j-4 \\
f^{*}\left(v_{j} u_{j+2}\right)=20 j+5 \\
f^{*}\left(u_{j} v_{j+1}\right)=4 j-1
\end{aligned}
$$

Thus, all the edge labeling are not repeated. Hence, the braid graph admits SDL and $\mathrm{B}(5)$ given below.

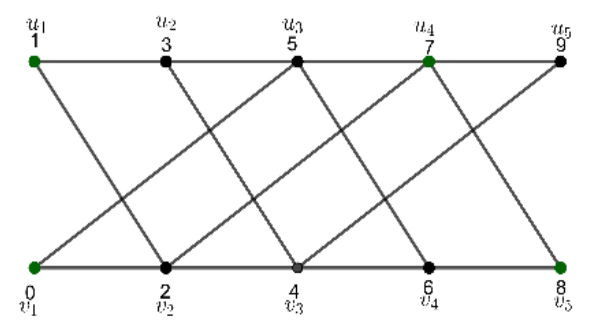

Fig 2. SDL for $B(5)$

\section{Theorem 2.3.}

The switching of an apex vertex of $\mathrm{CH}_{n}$ admits SDL.

\section{Proof:}

Consider the graph $\mathrm{G}$ with the vertex set $V(G)=\left\{x_{j}, y_{j}, w\right\}$

$1 \leq j \leq n\}$ and the edges $E(G)=\left\{x_{j} x_{j+1}, y_{j} y_{j+1}, x_{j} y_{j}, w y_{j}, x_{n}\right.$ $\left.x_{1,} y_{n} y_{1, w y_{j}} / \mathbb{1} \leq j \leq n-1\right\}$.

Clearly, $|\mathrm{V}(\mathrm{G})|=2 n$ and $|\mathrm{E}(\mathrm{G})|=3 n$

Now, define the vertex labeling $g$ and edge labeling $g{ }^{*}$ as

$$
\begin{aligned}
& g\left(x_{j}\right)=2 j \\
& g\left(y_{j}\right)=2 j-1 \\
& g(\mathrm{w})=0 \\
& g^{*}\left(x_{j} x_{j+1}\right)=8 j+4 \equiv 0(\bmod 4) \\
& g^{*}\left(y_{j} y_{j+1}\right)=8 j \equiv 0(\bmod 8) \\
& g^{*}\left(x_{n} x_{l}\right)=4 n^{2}-4 \\
& g^{*}\left(y_{n} y_{l}\right)=(2 n-1)^{2}-1 \\
& g^{*}\left(x_{j} y_{j}\right)=4 j-1 \\
& g^{*}\left(w y_{j}\right)=(2 j-1)^{2}
\end{aligned}
$$

Hence, all the edge labeling are satisfied the condition of square difference labeling. Therefore, the theorem is verified. For instance, switching of an apex vertex of $\mathrm{CH} 4$ given.

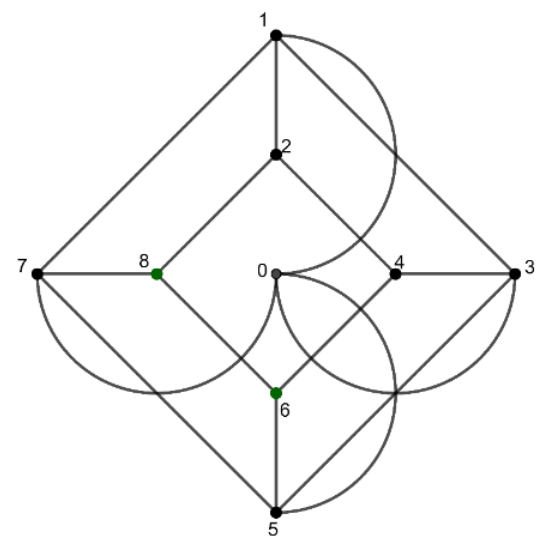

Fig. 3. SDL of switching graph $\mathrm{CH} 4$

\section{Theorem 2.4.}

$T_{\mathscr{G}} \odot \mathrm{K}_{2}$ is $\mathrm{SDG}$.

\section{Proof:}

Let $v_{0,}, v_{i}, v_{i}^{b}, v_{i}^{n s}$ be the vertices and $v_{i} v_{i+1}, v_{6} v_{1}, v_{0} v_{1}, v_{0} v_{4}, v_{i} v_{i}^{s}$ be the edges of the graph $T_{C} \odot$ $\mathrm{K}_{2}$ with $\left|\mathrm{V}\left(T_{G} \odot \mathrm{K}_{2}\right)\right|=21$ and $\left|\mathrm{E}\left(T_{G} \odot \mathrm{K}_{2}\right)\right|=32$. Now determine the mapping $f: \mathrm{V} \rightarrow\{0,1,2 \ldots, n\}$

$$
\begin{aligned}
& f\left(v_{0}\right)=0 \\
& f\left(v_{i}\right)=i, 1 \leq i \leq 6 \\
& f\left(v_{i}^{f}\right)=i+7,0 \leq i \leq 6 \\
& f\left(v_{i j}^{v g}\right)=i+14,0 \leq i \leq 6 \\
& \text { and edge function } f^{*} \text { be } \\
& f^{*}\left(v_{i} v_{i+1}\right)=2 i+1,1 \leq i \leq 5 \\
& f^{*}\left(v_{i} v_{i}^{b}\right)=(i+1)^{2}-i^{2} \\
& f^{*}\left(v_{6} v_{1}\right)=35 \\
& f^{*}\left(v_{0} v_{1}\right)=1 \\
& f^{*}\left(v_{0} v_{4}\right)=16
\end{aligned}
$$

Thus, the induced function $f^{*}\left(e_{i}\right) \neq f^{*}\left(e_{j}\right) \forall e_{i}, e_{j} \in \mathrm{E}(\mathrm{G})$. Hence the theorem is proved and the example given below.

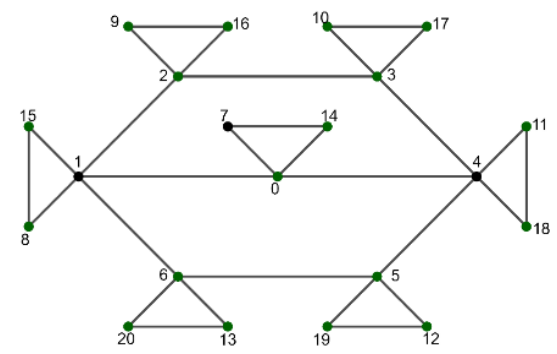

Fig.4. SDL for $T_{\mathbb{K}} \odot \mathrm{K}_{2}$

\section{Theorem 2.5.}

Bull graph $\left(C_{n}\right)$ is Square difference graph.

\section{Proof:}

Consider, $\mathrm{G}=$ bull $\left(\mathrm{C}_{\mathrm{n}}\right)$ with the vertex set $\mathrm{V}=\left\{x_{i}, \mathrm{w}_{1}, \mathrm{w}_{2}\right\}$ $1 \leq i \leq n\}$ and the edge set $\mathrm{E}=\left\{x_{i} x_{i+1}, x_{n} x_{1}, w_{1} x_{1}, w_{2} x_{2} /\right.$ $1 \leq i \leq n-1\}$ and also with the cardinality of vertices and edges be $n+2$. 
Define, the vertex function $f$ as

$$
\begin{aligned}
& f\left(x_{j}\right)=i+1 \\
& f\left(w_{1}\right)=0 \\
& f\left(w_{2}\right)=1
\end{aligned}
$$

and the edge function $f^{*}$ as

$$
\begin{aligned}
& f^{*}\left(x_{i} x_{i+1}\right)=2 i+3 \\
& f^{*}\left(x_{n} x_{1}\right)=[n+1]^{2}-4 \\
& f^{*}\left(w_{1} x_{1}\right)=4 \\
& f^{*}\left(w_{2} x_{2}\right)=8
\end{aligned}
$$

Thus, the edge in $\mathrm{E}$ have distinct labels. Therefore, the theorem is verified.

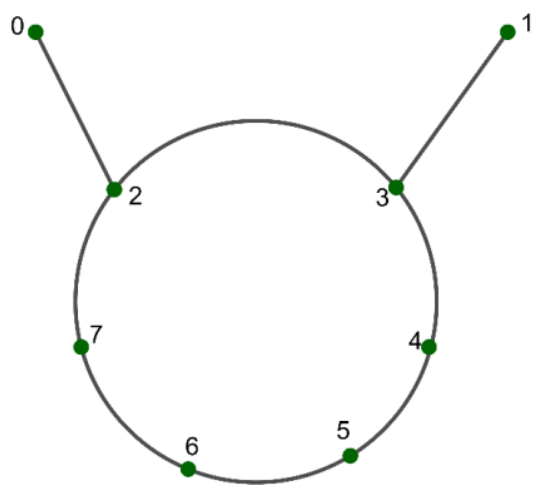

Fig. 5. Bull $\left(\mathbf{C}_{6}\right)$

\section{Theorem 2.6.}

The truncated tetrahedron graph admits Square difference labeling.

\section{Proof:}

Let the truncated graph is obtained with 12 vertices and 18 edges. $v_{j}$ be the vertices for $\mathrm{j}=1,2, \ldots, 12$.

Define the bijective function $g$ as

$$
g\left(v_{j}\right)=j-1
$$

and the induced function $g *$ as

$$
\begin{aligned}
& g^{*}\left(v_{i} v_{i+1}\right)=2 j-1,5 \leq i \leq 12 \\
& g *\left(v_{1} v_{3}\right)=4 \\
& g *\left(v_{1} v_{5}\right)=16 \\
& g^{*}\left(v_{1} v_{6}\right)=25 \\
& g^{*}\left(\mathrm{v}_{2} \mathrm{v}_{4}\right)=8 \\
& g^{*}\left(\mathrm{v}_{2} \mathrm{v}_{7}\right)=35 \\
& g^{*}\left(\mathrm{v}_{2} \mathrm{~V}_{\mathrm{g}}\right)=48 \\
& g *\left(\nu_{a} v_{g}\right)=60 \\
& g^{*}\left(\mathrm{v}_{\mathrm{a}} \mathrm{D}_{10}\right)=77 \\
& g *\left(v_{4} v_{11}\right)=91 \\
& g *\left(\mathbb{V}_{4} V_{12}\right)=112 \\
& g^{*}\left(v_{12} v_{5}\right)=105
\end{aligned}
$$

Clearly, the edge labels defined above are all distinct. Hence the theorem. The truncated tetrahedron graph for SDL given below:

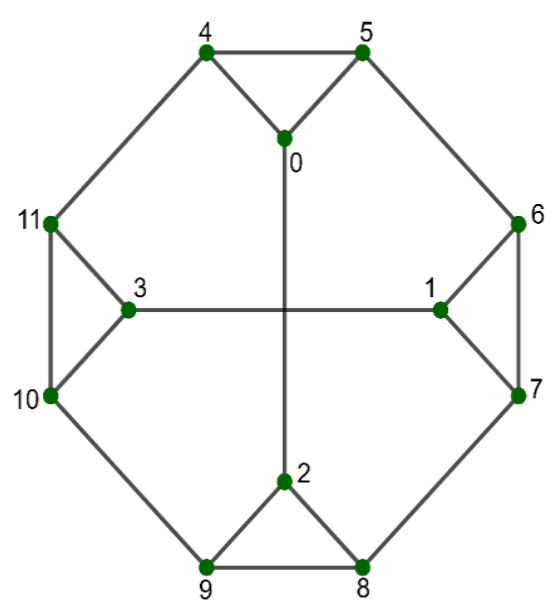

Fig. 6. SDL for Truncated tetrahedron

\section{Theorem 2.7.}

The Frutcht graph admits SDG.

\section{Proof:}

Consider the graph $\mathrm{G}$ be the Frutcht graph with 12 vertices and 18 edges.

Let $u_{j}$ be the vertex set for $1 \leq j \leq 12$.

Then label the vertex $u_{j}$ as $j-1$ and the edge labels as

$$
\begin{aligned}
& f^{*}\left(v_{j} v_{i+1}\right)=2 j-1,1 \leq i \leq 12 \\
& f^{*}\left(v_{1} v_{9}\right)=64 \\
& f^{*}\left(v_{2} v_{10}\right)=80 \\
& f^{*}\left(v_{9} v_{10}\right)=76 \\
& f^{*}\left(v_{4} v_{11}\right)=91 \\
& f^{*}\left(v_{5} v_{11}\right)=84 \\
& f^{*}\left(v_{6} v_{9}\right)=24 \\
& f^{*}\left(v_{7} v_{1}\right)=36 \\
& f^{*}\left(v_{7} v_{9}\right)=13 \\
& f^{*}\left(v_{9} v_{12}\right)=57 \\
& f^{*}\left(v_{10} v_{12}\right)=40 \\
& f^{*}\left(v_{11} v_{12}\right)=21
\end{aligned}
$$

For the above vertex labeling we receive the distinct edge labels. Hence the theorem.

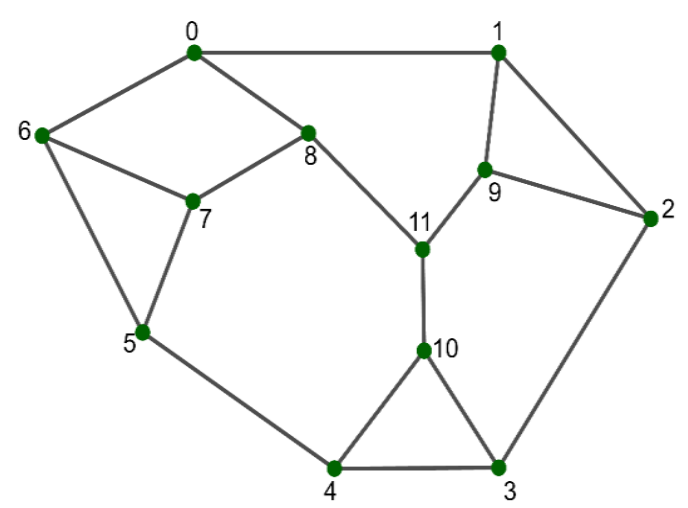

Fig. 7. Frutcht graph 


\section{Considering Square Difference Labelling for Validating Theta Graphs of Dynamic Machinaries}

\section{CONCLUSION}

In this paper we discussed some special graphs like Z- $\mathrm{P}_{\mathrm{n}}$, braid graph, switching of an apex vertex of $\mathrm{CH}_{\mathrm{n}}, T_{\tilde{\Pi}} \odot \mathrm{K}_{2}$, bull graph $\left(\mathrm{C}_{\mathrm{n}}\right)$, truncated tetrahedron, frutcht graph are Square difference graph (SDG).

\section{REFERENCES}

1. J. Arthy, K. Manimekalai, K. Ramanathan, "Cycle and path related graphs on L - Cordial labeling”, International Journal of Innovative Science and Research Technology, Vol 4, issue 6, June 2019.

2. Frank Harary "Graph Theory”, Narosa Publishing House, 2001.

3. Gallian J.A "A Dynamic Survey of Graph Labeling”, The Electronic Journal of Combinatorics, \#DS6, 2017.

4. Jagadeeswari. P, K. Ramanathan and K. Manimekalai, "Square Difference Labeling for pyramid graph and its related graphs", International journal of Mathematics And its Applications”, 6(1) (2018) 91-96.

5. Jagadeeswari. P, K. Manimekalai and, K. Ramanathan, "Square Difference Labeling for H Graphs", AIP Conference Proceedings 2112, 020147 (2019); https://doi.org/10.1063/1.5112332. Published Online: 24 June 2019.

6. Mukund V Bapat, "New results on L - cordial labeling of graphs", International Journal of Statistics and applied Mathematics, 2018: 3(2); $641-644$.

7. N. B. Rathod, K. K. Kanani, "4 - cordiality of some new path related graphs", International Journal of Mathematics Trends and Technology, Vol 34, No.1, May 2016.

8. Rosa A “On Certain Valuation of Graph Theory of Graph", (Rome, July 1966), Golden \& Breach .M and Paris (1967), 349 - 355.

9. Shiama.J. "Square difference labeling for some graphs" International Journal of Computer Applications (0975-08887), Vol.44 (4), April 2012.

10. Shiama.J. "Some Special types of Square difference graphs" International Journal of Mathematical archives, Vol. 3(6), 2012, 2369-2374 ISSN 2229-5046.

11. G. Subashini, K. Bhuvaneswari, K. Manimekalai, "Square Difference labeling of Theta Graphs", International Journal of Engineering and Research Vol-8, issue 9.

12. P. Sumathi, "Quotient 3 cordial labeling for some special graphs", International of Journal Innovative research in Pure and Engineering Mathematics, vol 1, issue 1, 2017.

\section{AUTHORS PROFILE}

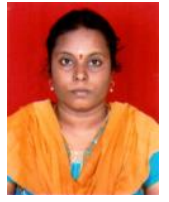

P. Jagadeeswari is an Assistant Professor, Department of Science and Humanities, BIHER, Chennai. She is currently working on Graph labeling. She published 7 papers in international journal. 